\title{
Vitamin D status in women with dichorionic twin pregnancies and their neonates: a pilot study in China
}

Xin $\mathrm{Li}^{1,2,3 \dagger}$, Jiaxiao $\mathrm{Yu}^{1,2,3 \dagger}$, Li Wen ${ }^{1,2,3 \dagger}$, Qingshu Li ${ }^{2,3,4}$, Jianying Yan ${ }^{5}$, Jing Tian ${ }^{6}$, Chao Tong ${ }^{1,2,3,7^{*}}$ (D), Qi Tong ${ }^{7^{*}}$, Hongbo Qi ${ }^{1,2,3,4^{*}}$, Richard Saffery ${ }^{3,8}$, Mark D. Kilby ${ }^{9,10}$ and Philip N. Baker ${ }^{3,11}$

\begin{abstract}
Background: Vitamin D deficiency is a global public health issue in women and children and is associated with adverse impacts on child growth, such as rickets. However, prior studies have mainly focused on measuring vitamin $\mathrm{D}$ levels in singleton pregnant women and their offspring, and very limited studies have revealed the prevalence of vitamin D deficiency in twin pregnant women and their offspring. The aim of this study was to investigate vitamin $\mathrm{D}$ levels in twin-pregnant women and their neonates. We also explored the correlation of maternal vitamin $\mathrm{D}$ levels with neonatal outcomes and infant growth.
\end{abstract}

Methods: A prospective subcohort investigation was carried out among 72 dichorionic, diamniotic twin-pregnant mothers and their twin offspring from the Longitudinal Twin Study. Peripheral blood was collected from the mothers in the third trimester, and cord blood was collected from neonates at birth to identify 25[OH]D levels. Data on the characteristics of the mothers and neonates were collected. Infant growth data and food sensitivities were also collected.

Results: The average maternal 25[OH]D level was $31.78 \mathrm{ng} / \mathrm{mL}$, with $19.4 \%$ being deficient and $20.8 \%$ insufficient, while the average neonatal 25[OH]D level was $15.37 \mathrm{ng} / \mathrm{mL}$, with $99.3 \%$ being deficiency or insufficient. A positive correlation was found between maternal and neonatal 25[OH]D levels (beta-value: 0.43, 95\% Cl: 0.37, 0.49). Interestingly, the higher the maternal 25[OH]D level was, the smaller the cotwin birthweight discordance (betavalue: $-2.67,95 \% \mathrm{Cl}:-5.11,-0.23)$. In addition, the infants of mothers with vitamin $\mathrm{D}$ deficiency were more likely to be allergic to foods at 6 months than those of mothers with vitamin $D$ sufficiency.

Conclusions: Twin neonates were at high risk of vitamin D deficiency, although their mothers' vitamin D deficiency partially improved. Higher maternal vitamin D levels were associated with smaller discordance of cotwin birthweight.

Trial registration: Chinese Clinical Trial Registry ChiCTR-OOC-16008203, 1st April 2016.

Keywords: Vitamin D, Twin pregnancies, Neonates, Prospective study, Nutrition

\footnotetext{
*Correspondence: chaotongcqmu@163.com; 167570342@qq.com; qihongbo728@163.com

${ }^{+}$Xin Li, Jiaxiao Yu and Li Wen contributed equally to this work.

'Department of Obstetrics, The First Affiliated Hospital of Chongqing Medical

University, 1 Youyi Road, Yuzhong District, Chongqing 400016, China

${ }^{7}$ Chongaing Population and Family Planning Science and Technology

Research Institute, 18 Honghuang Rd, Jiangbei District, Chongqing 400020,

China

Full list of author information is available at the end of the article
}

(c) The Author(s). 2021 Open Access This article is licensed under a Creative Commons Attribution 4.0 International License, which permits use, sharing, adaptation, distribution and reproduction in any medium or format, as long as you give appropriate credit to the original author(s) and the source, provide a link to the Creative Commons licence, and indicate if changes were made. The images or other third party material in this article are included in the article's Creative Commons licence, unless indicated otherwise in a credit line to the material. If material is not included in the article's Creative Commons licence and your intended use is not permitted by statutory regulation or exceeds the permitted use, you will need to obtain permission directly from the copyright holder. To view a copy of this licence, visit http://creativecommons.org/licenses/by/4.0/. The Creative Commons Public Domain Dedication waiver (http://creativecommons.org/publicdomain/zero/1.0/) applies to the data made available in this article, unless otherwise stated in a credit line to the data. 


\section{Background}

Vitamin D is a potent steroid hormone that is not only essential for building and maintaining bones but also plays an important role in the immune, endocrine and cardiovascular systems [1-4]. Although both animal-derived and plant-derived food sources can provide some vitamin D, the main source of vitamin D in the body depends on exposure to sunlight $[5,6]$. However, the amount of time that people spend in the sun in modern society is not enough to meet their vitamin $D$ needs $[7,8]$, especially since excessive ultraviolet radiation causes skin problems. In addition, ethnicity, latitude and body mass index also influence vitamin D status [9-11].

Vitamin D deficiency is a global public health problem, especially among pregnant women and newborns [12, 13]. A deficiency of vitamin $\mathrm{D}$ in pregnant women increases the risk of gestational diabetes, gestational hypertension disorder and insufficient gestational weight gain and may affect fetal growth and bone ossification [14, 15]. Patients with vitamin $\mathrm{D}$ deficiency have been shown to have a higher risk of calcemia and respiratory distress syndrome and a higher likelihood of developing food sensitivities, asthma, type I diabetes or autism later in life [16-20]. Previous studies have revealed that vitamin $\mathrm{D}$ status in the fetus and newborn is largely dependent on maternal vitamin D status; thus, the main risk factor for newborn vitamin D deficiency is maternal vitamin D deficiency [2123]. However, the data on vitamin D status among twinpregnant women and their offspring are very limited.

In recent decades, the prevalence of twin pregnancies has increased 1.8-fold according to the National Vital Statistics Report of the US due to the development of assisted reproductive technology and advanced maternal age [24-26]. In comparison with those with singleton pregnancy, women who are pregnant with twins are considered to undergo more complex physiological changes and obviously have a higher risk of adverse obstetric consequences [27, 28]. More attention should be paid to twin pregnancies with respect to nutrition and vitamin supplementation. Thus, it is essential to clarify whether vitamin $\mathrm{D}$ deficiency in mothers and newborns worsens among twin pregnancies.

Therefore, in the present study, we aimed to investigate the status of $25[\mathrm{OH}] \mathrm{D}$ in mothers and their newborns in a twin pregnancy and birth cohort from Southwest China. Given the previous findings reported for singleton pregnancy, we also aimed to determine the impact of maternal 25[OH]D deficiency on maternal and neonatal outcomes as well as child growth.

\section{Methods}

\section{Study design and participants}

The present study was embedded in the Longitudinal Twin Study (LoTiS), an ongoing twin pregnancy and birth cohort study conducted in Chongqing, which aims to determine the relative contributions of genes and the environment to early-onset intermediate phenotypes related to later adult onset disease. Chongqing is situated in southwestern China at a latitude of $29.35^{\circ} \mathrm{N}$ and characterized by a subtropical monsoon humid climate. This city has insufficient sunshine (1000-1400 h/year), especially in winter and spring. The LoTiS twin cohort study was established in January 2016 and aims to unravel the complex interplay between genes and the environment in specifying early life determinants of illness in infancy (Chinese Clinical Trial Registration Number: ChiCTR-OOC-16008203) and was approved by the Ethics Committee of the First Affiliated Hospital of Chongqing Medical University (No. 201530). Written informed consent was obtained from all participants. This subgroup study included dichorionic twin pregnant women confirmed prenatally by ultrasound with a prepregnancy BMI in the normal range $(18.5 \sim 23.9)$ as well as daily multivitamin (vitamin D: $500 \mathrm{IU}$ ) supplementation from the first trimester to delivery. Due to the high incidence of adverse outcomes in monochorionic twin pregnancies, they were excluded from this study. Therefore, this study investigated vitamin D status in dichorionic diamniotic twin pregnancies. In addition, previous studies have shown that obese pregnant women may have abnormal vitamin D intake $[29,30]$, so we only included pregnant women with normal prepregnancy BMI. Mothers with chronic metabolic diseases and those using immunosuppressants were excluded. Twin pairs with a birth weight $<1500 \mathrm{~g}$, significant malformations, or genetic disorders were also excluded. All twin offspring received daily usage of vitamin D supplements (400 IU/day) from birth and had a pediatric follow-up visit thereafter at a corrected age of 6 months.

\section{Data collection}

Maternal sociodemographic data (age, height, weight, education, occupation, parity, mode of conception), lifestyle behaviors before pregnancy (smoking and alcohol use) and pre-existing conditions were collected by standardized questionnaire in the first follow-up during 11-16 gestational weeks. The standardized questionnaire was self-designed for the LoTiS cohort study, and detailed information is presented in Supplemental File 1. Information about vitamin D supplementation and other nutrients was collected using a structured questionnaire during the third trimester. Detailed information on this questionnaire is presented in Supplemental File 2. Pregnancy complications and maternal and neonatal outcomes, including gestational age, preterm premature rupture of membranes (PPROM, < 37 gestational weeks), neonatal sex, birthweight and smallfor-gestational age (SGA, defined as a weight below the 
10th percentile for GA and sex [31]), were collected from medical records.

Measurement of serum 25[OH]D and classification criteria Peripheral blood samples were collected from the mothers in the third trimester, and cord blood samples were immediately collected from newborns after placental delivery by using a coagulation-promoting blood collection tube. The specimen was transported to the Maternal and Fetal Medical Laboratory under refrigeration, where they were centrifuged to obtain serum. The serum 25[OH]D level was measured by high-performance liquid chromatographyelectrospray tandem mass spectrometry (HPLC-MS-MS, Waters, USA), which is the gold standard method [32]. The concentrations of $25[\mathrm{OH}] \mathrm{D}_{3}$ and $25[\mathrm{OH}] \mathrm{D}_{2}$ were measured separately, and the total level of $25[\mathrm{OH}] \mathrm{D}$ was the sum of $25[\mathrm{OH}] \mathrm{D}_{3}$ and $25[\mathrm{OH}] \mathrm{D}_{2}$.

Serum $25[\mathrm{OH}] \mathrm{D}$ is the best estimator to assess body vitamin D levels in the body [33]. For analysis, we divided mothers into 3 groups based on 25[OH]D levels: $25[\mathrm{OH}] \mathrm{D}$ levels $<20 \mathrm{ng} / \mathrm{mL}$ indicated deficiency, 25[OH]D levels in the range of 20-30 ng/mL indicated insufficiency, and 25[OH]D levels $>30 \mathrm{ng} / \mathrm{mL}$ were considered sufficiently high [34]. The same cutoffs were used for neonates according to the Chinese standard [35].

\section{Infant growth assessment and skin prick test}

Infant growth was monitored for weight and length at the corrected age of 6 months. The corrected age was defined as the infant's chronological age minus the difference between term birth ( 40 weeks) and chronological gestational weeks of delivery. Weight and length were simultaneously measured unclothed by a digital measuring bed (Beideneng, Shanghai, China) operated by trained nurses at the Department of Child Health Care of Chongqing Health Center for Women and Children. The indexes of weight, height and BMI were converted to Z-scores for sex and age according to WHO Child Growth Standards software (https://www.who.int/ childgrowth/software/en/).

On the same day, a skin prick test (SPT) was performed to preliminarily diagnose food allergies. The SPT was performed on the volar surface of the forearm with a lancet through the use of a drop of an allergen extract, and test results were produced in 15 to $20 \mathrm{~min}$. The routine test screened for food types including milk, egg white, egg yolk, peanut, fish, wheat, soybean, citrus, and apple.

\section{HPLC-MS-MS}

The mass spectrometry conditions were an electrospray ionization source with multiple reaction ion scanning modes. Voltages: capillary $(3 \mathrm{kV})$, cone $(20 \mathrm{~V})$, source offset $(50 \mathrm{~V})$, temperature $\left(400^{\circ} \mathrm{C}\right)$. GAS Flow: Desolvation
(800 L/Hr), Cone (150 L/Hr), Nebulizer (7.0 The calibration curve showed good linearity over the range of $1-80$ $\mathrm{ng} / \mathrm{mL}$ for $25[\mathrm{OH}] \mathrm{D}_{2}$ and $4-200 \mathrm{ng} / \mathrm{mL}$ for $25[\mathrm{OH}] \mathrm{D}_{3}$, with $< \pm 15 \%$ RSD and RE. The intra-assay and inter-assay coefficients of variation were $<15 \%$ in all assays, indicating good repeatability.

\section{Statistical methods}

All statistical analyses were performed with SPSS version 25.0 (IBM, Armonk, NY, USA). Categorical variables are presented as the count and percentage and were analyzed by the chi-squared or Fisher's exact test. Continuous variables are presented as the means and standard deviation and were analyzed by Student's t-test, LSD Student's t test, one-way analysis of variance or the nonparametric test. Linear correlation analysis was used to explore the correlation between $25[\mathrm{OH}] \mathrm{D}$ levels in mothers and newborns and the correlation of $25[\mathrm{OH}] \mathrm{D}$ levels between cotwins. Multivariable linear regression analysis was used to detect the associations between neonatal 25[OH]D levels and related clinical characteristics. All tests were two-tailed, and $p<0.05$ was considered statistically significant.

\section{Results}

The selection process for this study population is presented in Fig. 1. A total of 190 dichorionic twin pregnancies from LoTiS were initially recruited into this subgroup study. After excluding mother-twin offspring pairs that did not meet the inclusion criteria and did not have blood samples, a total of 72 mother-twin offspring pairs were available for the final analysis. The descriptive data of the study participants are shown in Table 1 . The average maternal age at recruitment was $30.46 \pm 2.93$ years, and the average gestational age was $36.77 \pm 1.16$ weeks. The mean birth weight of all neonates was $2626.53 \pm 329.96 \mathrm{~g}$. In addition, $62.5 \%$ of mothers conceived with the aid of assisted reproductive technology (ART), and $66.7 \%$ of mothers delivered in the summer or autumn. The average maternal $25[\mathrm{OH}] \mathrm{D}$ level was $31.78 \pm 11.1 \mathrm{ng} / \mathrm{mL}$, with $19.5 \%$ of mothers being deficient and $20.8 \%$ being insufficient. Unexpectedly, the average neonatal 25[OH]D level was $15.37 \pm 4.86 \mathrm{ng} / \mathrm{mL}$, with $78.5 \%$ of neonates being deficient and $20.8 \%$ being insufficient.

In the maternal vitamin D deficiency group, over half of the mothers conceived with ART and were complicated with gestational diabetes, and $78.6 \%$ delivered in the winter or spring; this group had the highest incidence of SGA, with the lowest birthweight as well as the highest birthweight discordance (Table 2).

A significant difference in neonatal 25[OH]D levels was found among the maternal vitamin D deficiency, insufficiency and sufficiency groups (Table 2). There was a 


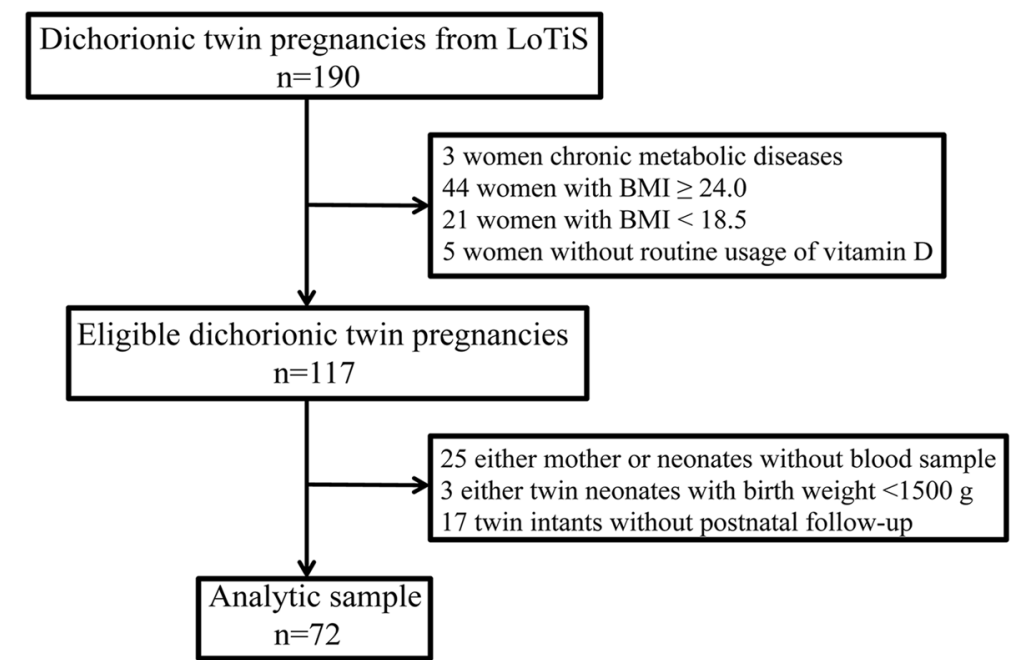

Fig. 1 The selection process for this study

Table 1 Description of the maternal and neonatal characteristics

\begin{tabular}{ll}
\hline Variables & Total \\
\hline Mothers & 72 \\
Age (year) & $30.46 \pm 2.93$ \\
Pre-pregnancy BMI $(\mathrm{kg} / \mathrm{m} 2)$ & $21.15 \pm 1.32$ \\
Mode of conception & \\
Natural conception & $27(37.5 \%)$ \\
Assisted reproductive technology & $45(62.5 \%)$ \\
Gestational weight gain $(\mathrm{kg})$ & $17.65 \pm 5.89$ \\
Gestational age $(\mathrm{week})$ & $36.77 \pm 1.16$ \\
Preterm birth & $33(45.8 \%)$ \\
Sampling season & \\
Summer/autumn & $24(33.3 \%)$ \\
Winter/spring & $48(66.7 \%)$ \\
25[OH]D level $(\mathrm{ng} / \mathrm{mL})$ & $31.78 \pm 11.1$ \\
Deficiency $(<20 \mathrm{ng} / \mathrm{mL})$ & $14(19.5 \%)$ \\
Insufficiency $(20-30 \mathrm{ng} / \mathrm{mL})$ & $15(20.8 \%)$ \\
Sufficiency $(>30 \mathrm{ng} / \mathrm{mL})$ & $43(59.7 \%)$ \\
Infants & 144 \\
Gender (male) & $70(48.6 \%)$ \\
Birthweight (g) & $2626.53 \pm 329.96$ \\
SGA & $5(3.5 \%)$ \\
$25[O H] D$ level $(\mathrm{ng} / \mathrm{mL})$ & $15.37 \pm 4.86$ \\
Deficiency (<20 ng/mL) & $113(78.5 \%)$ \\
Insufficiency $(20-30 \mathrm{ng} / \mathrm{mL})$ & $30(20.8 \%)$ \\
Sufficiency (> 30 ng/mL) & $1(0.7 \%)$ \\
\hline
\end{tabular}

directly proportional correlation between maternal $25[\mathrm{OH}] \mathrm{D}$ levels and neonatal 25[OH]D levels $(r=0.90$, $p<0.001$ ) (Fig. 2a). In addition, a significantly positive correlation was found between cotwins in terms of neonatal 25[OH]D level $(r=0.91, p<0.001)$ (Fig. 2b). Multivariable linear regression showed that neonatal $25[\mathrm{OH}] \mathrm{D}$ levels were positively associated with maternal 25[OH]D levels (beta-value: 0.968, 95\% CI: 0.459,0.531. $p<0.001$ ) and birth season (beta-value: $-0.102,95 \% \mathrm{CI}$ : - 1.013, 0.198. $p=0.004$ ) and were not found to have a correlation with maternal age, BMI, gestational weight gain, gestational age, GDM, GHP, ICP or neonatal birthweight (Table 3).

The neonatal birthweight and the discordance in birthweight between cotwins were significantly different between the maternal 25[OH]D deficiency and sufficiency groups (Fig. 3a-c). After adjusting for maternal age, BMI, GDM, GHP, ICP, gestational weight gain, gestational age and birth season, the results suggested that there was no correlation between maternal 25[OH]D levels and neonatal birthweight (Table 4). Surprisingly, maternal $25[\mathrm{OH}] \mathrm{D}$ levels were negatively correlated with the discordance in birthweight between cotwins, with the discordance in birthweight between cotwins decreasing by $2.67 \%$ when the maternal $25[\mathrm{OH}] \mathrm{D}$ level increased by 1 $\mathrm{ng} / \mathrm{mL}$ (95\% CI: $-5.11,-0.23 . p=0.032$ ) (Fig. 3c).

At 6 months of corrected age, the $\mathrm{z}$-scores of the weight-for-age, height-for-age, weight-for-height, and BMI-for-age indexes showed no differences among the maternal 25[OH]D deficiency, insufficiency and sufficiency groups for all infants taking vitamin D supplements each day. However, in the maternal vitamin D deficiency group, the incidence of allergies to foods was highest (Table 5). 
Table 2 Description of the maternal and neonatal characteristics by maternal vitamin D status

\begin{tabular}{|c|c|c|c|c|}
\hline Variables & Deficiency & Insufficiency & Sufficiency & $p$-value \\
\hline Mothers & $N=14$ & $N=15$ & $N=43$ & \\
\hline Age (year) & $29.86 \pm 3.57$ & $29.87 \pm 3.54$ & $30.86 \pm 3.52$ & $0.394^{a}$ \\
\hline Pre-pregnancy BMI (kg/m2) & $20.76 \pm 1.30$ & $20.50 \pm 1.26$ & $21.50 \pm 1.62$ & $0.054^{\mathrm{a}}$ \\
\hline Mode of conception & & & & $0.868^{b}$ \\
\hline Natural conception & $6(42.9 \%)$ & $5(33.3 \%)$ & $16(37.2 \%)$ & \\
\hline ART & $8(57.1 \%)$ & $10(66.7 \%)$ & $27(62.8 \%)$ & \\
\hline Pregnancy weight gain $(\mathrm{kg})$ & $17.50 \pm 4.97$ & $19.43 \pm 4.44$ & $17.07 \pm 6.55$ & $0.412^{a}$ \\
\hline Gestational age (week) & $36.62 \pm 0.97$ & $36.98 \pm 1.08$ & $36.73 \pm 1.24$ & $0.473^{\mathrm{a}}$ \\
\hline Preterm birth & $7(50.0 \%)$ & $6(40.0 \%)$ & $20(46.5 \%)$ & $0.856^{\mathrm{b}}$ \\
\hline \multicolumn{5}{|l|}{ Pregnancy-induced illness } \\
\hline GDM & $8(57.1 \%)$ & $6(40.0 \%)$ & $12(27.9 \%)$ & $0.133^{b}$ \\
\hline GHD & $1(7.1 \%)$ & $1(6.7 \%)$ & $2(4.7 \%)$ & $0.510^{c}$ \\
\hline ICP & $4(28.6 \%)$ & $0(0 \%)$ & $8(18.6 \%)$ & $0.919^{c}$ \\
\hline Sampling season & & & & $0.538^{b}$ \\
\hline Summer/autumn & $3(21.4 \%)$ & $6(40.0 \%)$ & 15 (34.9\%) & \\
\hline Winter/spring & $11(78.6 \%)$ & $9(60.0 \%)$ & $28(65.1 \%)$ & \\
\hline Infants & $N=28$ & $N=30$ & $N=86$ & \\
\hline Gender (male) & $12(42.9 \%)$ & $19(63.3 \%)$ & 39 (45.3\%) & $0.188^{b}$ \\
\hline Birthweight (g) & $2453(365)$ & $2740(274)$ & 2641 (347) & $0.001^{d}$ \\
\hline Birthweight discordance (\%) & $8.83(1.21)$ & $6.93(3.87)$ & $5.72(4.06)$ & $0.048^{d}$ \\
\hline SGA & $2(7.1 \%)$ & $1(3.3 \%)$ & $2(2.3 \%)$ & $0.481^{c}$ \\
\hline 25[OH]D level (ng/mL) & $7.93(6.20)$ & $12.89(6.34)$ & $18.75(5.46)$ & $<0.001^{d}$ \\
\hline
\end{tabular}

$B M I$ body mass index, ART assisted reproductive technology, GDM gestational diabetes, GHD gestational hypertension disorder, ICP intrahepatic cholestasis of pregnancy, SGA small for gestational age

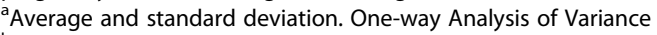

${ }^{\mathrm{b}}$ Number (percentage). Chi-squared Test

'Number (percentage). Fisher Exact Test

${ }^{\mathrm{d}}$ Median (interquartile range). Kruskal-Wallis Test

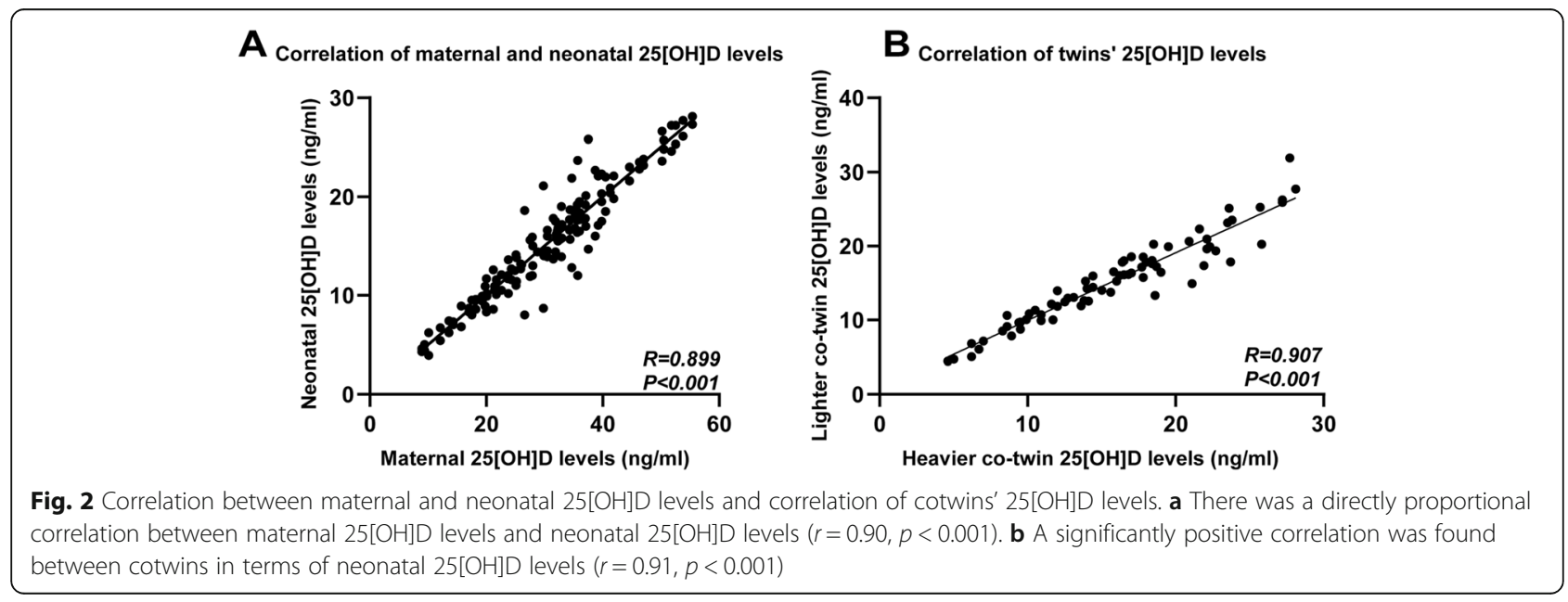


Table 3 Association between pregnant covariates and neonatal 25[OH]D levels

\begin{tabular}{llll}
\hline Variables & Beta & $\mathbf{9 5 \% ~ C l}$ & $\boldsymbol{P}$-value \\
\hline Maternal 25[OH]D level & 0.968 & $(0.459,0.531)$ & $<0.001$ \\
Maternal age & -0.019 & $(-0.347,0.209)$ & 0.622 \\
Maternal pre-pregnancy BMI & -0.002 & $(-0.114,0.109)$ & 0.965 \\
Maternal gestational weight gain & 0.015 & $(-0.056,0.084)$ & 0.684 \\
Gestational age at delivery & -0.187 & $(-0.649,0.276)$ & 0.423 \\
Birth season & -0.102 & $(-1.013,-0.198)$ & 0.004 \\
Neonatal birth weight & -0.020 & $(-0.002,0.001)$ & 0.672 \\
GDM & -0.019 & $(-1.042,0.598)$ & 0.591 \\
GHD & 0.029 & $(-1.056,2.461)$ & 0.427 \\
ICP & -0.013 & $(-0.522,0.399)$ & 0.791 \\
\hline
\end{tabular}

\section{Discussion}

In this prospective preliminary study, we reported that $19.5 \%$ of mothers had vitamin D deficiency, and their neonates had a remarkably high prevalence of vitamin $\mathrm{D}$ deficiency at birth, with a rate of $78.5 \%$. We noticed very poor vitamin D stores, especially in twin neonates, even though all mothers took multivitamins (including vitamin D: $500 \mathrm{IU})$ daily during pregnancy.

Several studies conducted on singleton pregnancy among the Chinese population have investigated maternal 25[OH]D levels. Maternal vitamin D deficiency was reported in $79.2 \%$ of a multiethnic population without an investigation of prenatal vitamin $\mathrm{D}$ supplementation [36]. Approximately $10 \%$ of mothers took prenatal vitamin $\mathrm{D}$, and the maternal vitamin $\mathrm{D}$ deficiency rate was also high at $74.9 \%$. If the mothers took prenatal vitamin $\mathrm{D}$ daily during the last month before delivery or over three times per week, the maternal vitamin D deficiency rates improved to 36.6 and $31.6 \%$, respectively [37]. The maternal vitamin $\mathrm{D}$ deficiency rate in this study was lower than that in the aforementioned studies. This can be explained by the fact that all subjects in this study took vitamin D supplements daily starting in the first trimester. Thus, we speculated that a high frequency of vitamin $\mathrm{D}$ supplementation during pregnancy is an effective way to reduce the risk of maternal vitamin $D$ deficiency.

Previous studies have revealed that the rates of maternal and neonatal vitamin D deficiency are comparable in singleton pregnancy $[36,38]$. A similar statement was also found in the northern Indian twin pregnancy population, with a maternal vitamin D deficiency rate of $90 \%$ and neonatal vitamin D deficiency rate of $89 \%$ [13]. However, the results of our study showed that the neonatal vitamin $\mathrm{D}$ deficiency rate was 4-fold higher than the maternal vitamin $D$ deficiency rate, which was inconsistent with the aforementioned study. This is probably attributed to the distinct rates of maternal vitamin $\mathrm{D}$ deficiency in the two studies. The significant difference in neonatal vitamin $\mathrm{D}$ deficiency and maternal vitamin D deficiency incidence in our study was likely due to the maternal vitamin D supply to the two fetuses. In addition, we also found that the maternal vitamin $\mathrm{D}$ level was an independent factor that correlated with the neonatal vitamin D level, which was consistent with previous studies [39].

The clinical practice guidelines of the Endocrinology Society recommend that pregnant women take vitamin D supplements of at least $600 \mathrm{IU}$ daily. However, twin neonates were at a very high risk of vitamin $\mathrm{D}$ deficiency
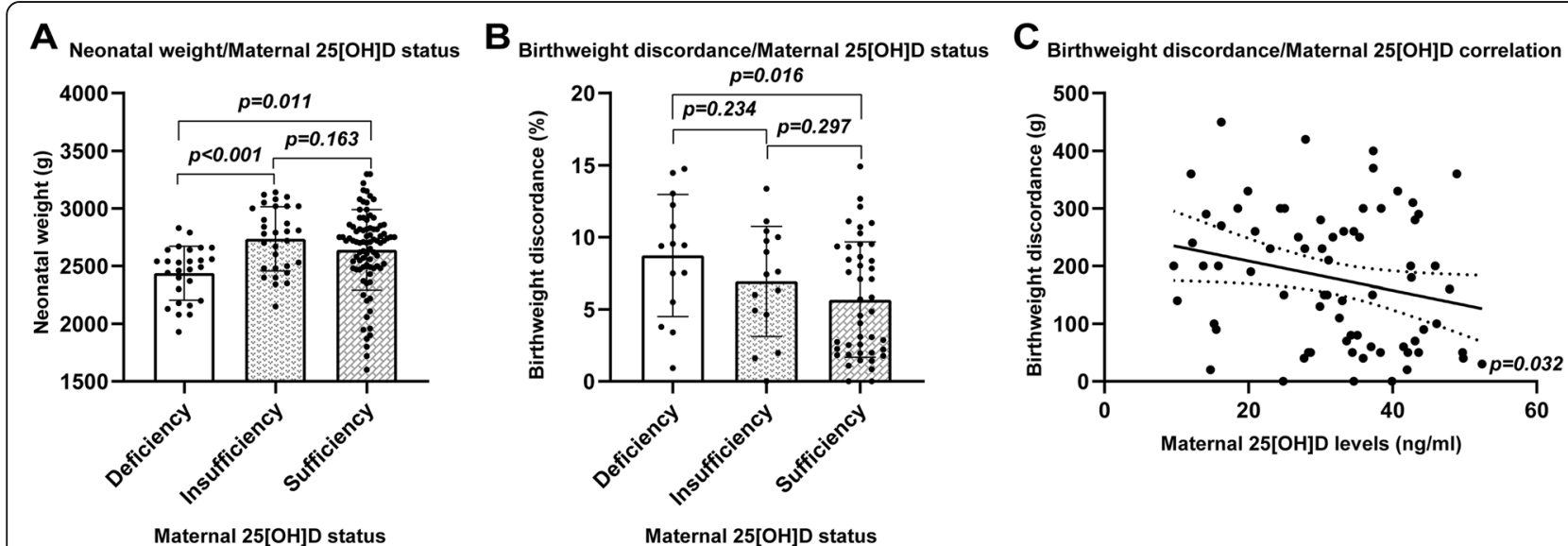

Fig. 3 The impact of maternal $25[\mathrm{OH}] \mathrm{D}$ levels on neonatal birthweight. a The neonatal birthweight was significantly different between the maternal 25[OH]D status (deficiency group vs insufficiency group, $P<0.001$; deficiency group vs sufficiency group, $P=0.011$ ); $\mathbf{b}$ The neonatal birthweight discordance(\%) was significantly different between the maternal 25[OH]D status (deficiency group vs sufficiency group, $P=0.016$ ); $\mathbf{c}$ Maternal 25[OH]D levels were negatively correlated with the discordance in birthweight between cotwins, with the discordance in birthweight between cotwins decreased 2.67\% when maternal 25[OH]D level increased by $1 \mathrm{ng} / \mathrm{mL}(95 \% \mathrm{Cl}:-5.11,-0.23 . p=0.032)$ 
Table 4 Association between pregnant covariates and neonatal birthweight

\begin{tabular}{llll}
\hline Variables & Beta & $\mathbf{9 5 \% ~ C l}$ & $\boldsymbol{P}$-value \\
\hline Maternal 25[OH]D level & 0.392 & $(-0.129,0.913)$ & 0.112 \\
Maternal age (years) & 1.104 & $(-0.193,2.400)$ & 0.139 \\
Maternal pre-pregnancy BMl & -0.189 & $(-2.107,1.728)$ & 0.095 \\
Maternal gestational weight gain & 0.007 & $(0.001,0.014)$ & 0.050 \\
Gestational age at delivery & 1.768 & $(-2.079,5.615)$ & 0.018 \\
Birth season & -2.489 & $(-4.544,-0.434)$ & 0.169 \\
GDM & 1.006 & $(-7.268,9.279)$ & 0.365 \\
GHD & 5.398 & $(0.010,10.787)$ & 0.810 \\
ICP & -0.226 & $(-0.549,0.097)$ & 0.845 \\
\hline
\end{tabular}

when twin pregnant women took vitamin D supplements of 500 IU daily. Therefore, further investigations are needed to establish an appropriate dose that is effective for improving neonatal vitamin D deficiency and safe for maternal metabolism.

Consistent with previous studies [40, 41], we found that newborns born in winter may have lower 25[OH]D levels. Chongqing, also known as China's fog capital, has few sunny days in winter. The long winter and lack of sunshine in Chongqing may be the cause of neonatal vitamin D deficiency.

There are conflicting reports about the association between maternal vitamin D levels and neonatal birthweight in singleton pregnancy. Hajianfar et al found a significant inverse association between maternal vitamin D level and the rate of low birthweight neonates [42]; others have reported no relationship [43, 44]. In our study, although the neonatal birthweight in the maternal vitamin $\mathrm{D}$ deficiency group was lower than that in the other group, no correlation was found between maternal vitamin $\mathrm{D}$ level and neonatal birthweight after adjusting for potential confounders. Interestingly, we found that the higher the maternal vitamin D level was, the smaller the discordance in birthweight between cotwins, thus presenting a negative association. However, further investigations are needed to detect the relative molecular mechanism.
Vitamin D deficiency in neonates has been shown to lead to a higher risk of food sensitivities later in life. In our study, because $99.3 \%$ of neonates were vitamin D deficient or insufficient, we compared the status of infants allergic to foods by maternal vitamin D levels. Although no significant difference was found among the maternal vitamin D deficiency, insufficiency and sufficiency groups in terms of allergies to foods, the allergy rate was highest in the maternal vitamin D deficiency group. It is worth exploring whether maternal vitamin $\mathrm{D}$ deficiency or neonatal vitamin $\mathrm{D}$ deficiency predominantly influences infant allergies to foods.

The strength of our study is the specialized study population. We used strict inclusion and exclusion criteria to screen the participants. Monochorionic twin pregnant women were not selected due to the higher risks of maternal and fetal complications, higher rate of preterm birth and lower neonatal birthweight. Prepregnancy BMI also has an obvious impact on perinatal outcomes, so we only recruited women with prepregnancy BMIs in the normal range. Additionally, the food sensitivities of infants at 6 months were followed, representing a relatively complete study design. Due to the low natural incidence of twin pregnancy [24], it is timeconsuming to obtain participants. Therefore, ART twin pregnancies were also recruited to enlarge the sample size of this study. This also conferred us the opportunity to investigate whether ART has an impact on the $25[\mathrm{OH}] \mathrm{D}$ levels of twin pregnancies, and our data clearly revealed that ART does not disturb maternal and neonatal vitamin $\mathrm{D}$ levels in twin pregnancies.

This preliminary study contributes new knowledge about the status of maternal and neonatal vitamin D levels in twin pregnancies, but several limitations of this study should be taken into consideration. First, compared with that of similar studies in singleton pregnancy, the sample size in this study was relatively small. Second, pregnant women in our hospital were routinely advised to take multivitamin supplements daily based on the clinical guidelines, particularly twin pregnant women; thus, there were no women who did not take multivitamin supplements as controls. Third, it is more appropriate to

Table 5 Description of the growth and food sensitivity by maternal 25[OH]D status

\begin{tabular}{lllll}
\hline Variables & $\begin{array}{l}\text { Deficiency } \\
(\boldsymbol{N}=\mathbf{2 8})\end{array}$ & $\begin{array}{l}\text { Insufficiency } \\
(\boldsymbol{N}=\mathbf{3 0})\end{array}$ & $\begin{array}{l}\text { Sufficiency } \\
(\boldsymbol{N}=\mathbf{8 6})\end{array}$ & $\begin{array}{l}\boldsymbol{p} \text {-value } \\
\text { WHZ }\end{array}$ \\
\hline WAZ & $0.39 \pm 0.80$ & $0.47 \pm 0.73$ & $0.35 \pm 0.82$ & $0.828^{\mathrm{a}}$ \\
HAZ & $0.41 \pm 0.88$ & $0.59 \pm 0.97$ & $0.34 \pm 0.85$ & $0.527^{\mathrm{a}}$ \\
BAZ & $0.29 \pm 1.10$ & $0.57 \pm 1.21$ & $0.42 \pm 0.95$ & $0.673^{\mathrm{a}}$ \\
Allergic to one or more food & $0.34 \pm 0.66$ & $0.38 \pm 0.98$ & $0.36 \pm 0.79$ & $0.981^{\mathrm{a}}$ \\
\hline
\end{tabular}

WHZ z-score for weight-for-height, WAZ z-score for weight-for-age, HAZ z-score for height-for-age, BAZ z-score for BMI-for-age

${ }^{a}$ Average and standard deviation. Student t test

${ }^{\mathrm{b}}$ Number (percentage). chi-square test 
measure vitamin D levels in women pregnant with twins in the first trimester, prescribe adequate dose supplements and monitor vitamin $\mathrm{D}$ levels during pregnancy. Then, the related variables of vitamin $\mathrm{D}$ metabolism were limited, such as dietary vitamin D intake and daily solarization not involved. Finally, singleton pregnant women taking the same multivitamin supplements and their neonates should be included as a control group. A large-scale study including singleton pregnancy and twin pregnancies conducted in multiple centers is essential to better understand the prevalence of maternal and neonatal vitamin $\mathrm{D}$ deficiency in China among twin pregnancy populations.

\section{Conclusions}

In summary, this study suggested that despite twinpregnant women taking prenatal vitamin D supplements and the mothers' vitamin D deficiency partially improving, their twin neonates were at high risk of vitamin $\mathrm{D}$ deficiency. These findings indicated that obstetricians should pay special attention to the dose of vitamin supplements provided to the twin pregnancy population.

\section{Abbreviations}

NC: Natural conception group; IVF: In vitro fertilization; BMI: Body mass index; Cl: Confidence interval; GA: Gestational age; GDM: Gestational diabetes mellitus; ICP: Intrahepatic cholestasis of pregnancy; LoTiS: Longitudinal Twin Study; OR: Odds ratio; PE: Preeclampsia; SGA: Small for gestational age; ART: Assisted reproductive technology; GHD: Gestational hypertension disorder; WHZ: Z-score for weight-for-height; WAZ: Z-score for weight-forage; HAZ: Z-score for height-for-age; BAZ: Z-score for BMl-for-age

\section{Supplementary Information}

The online version contains supplementary material available at https://doi. org/10.1186/s12884-021-03707-7.

Additional file 1.

Additional file 2 .

\section{Acknowledgments}

The authors would like to thank all the participants, Beijing Health Biotech Co. Ltd., health professionals and researchers who contributed to this cohort study.

\section{Authors' contributions}

$\mathrm{CT}$ and LW designed the research protocol; $\mathrm{XL}$ and JY1 conducted the study; $\mathrm{XL}$ and JT analyzed the data; $\mathrm{XL}$ drafted the manuscript; $\mathrm{WL}, \mathrm{CT}, \mathrm{QL}, J \mathrm{Y} 2, \mathrm{RS}$, MDK, PB critically revised the manuscript; CT, QT, HQ provided funding resources. All authors have accepted responsibility for the entire content of this submitted manuscript and approved submission.

\section{Funding}

This study was supported by grants from National Key Research and Development Program of China (2018YFC1002900), National Natural Science Foundation of China (81520108013 and 81771613), Chongqing Science and Technology Commission (cstc2017jcyjBX0045), and NHC Key Laboratory of Birth Defects and Reproductive Health (2018-5). The funding agencies did not have any role in the design of the study, collection, analysis, and interpretation of data, and in writing the manuscript.

\section{Availability of data and materials}

The LoTiS is being conducted mainly at the First Affiliated Hospital of Chongqing Medical University and Chongqing Women and Children's Health
Center, where the staff are responsible for the collection, management, and distribution of data. All data are stored electronically in an anonymous format and are currently only available to LoTiS researchers. The datasets used and/or analyzed during the current study are available from the corresponding author upon request (chaotongcqmu@163.com).

\section{Declarations}

Ethics approval and consent to participate

The experimental design and procedures were approved by the Ethics Committee of the First Affiliated Hospital of Chongqing Medical University (No. 201530). All participants gave signed informed consent for participation in research.

\section{Consent for publication}

Not applicable.

\section{Competing interests}

The authors declare that they have no competing interests.

\section{Author details}

'Department of Obstetrics, The First Affiliated Hospital of Chongqing Medical University, 1 Youyi Road, Yuzhong District, Chongqing 400016, China. ${ }^{2}$ State Key Laboratory of Maternal and Fetal Medicine of Chongqing Municipality, Chongqing Medical University, Chongqing 400016, China. ${ }^{3}$ International Collaborative Laboratory of Reproduction and Development of Chinese Ministry of Education, Chongqing Medical University, Chongqing 400016, China. ${ }^{4}$ Department of Pathology, The First Affiliated Hospital of Chongqing Medical University, Chongqing 400016, China. ${ }^{5}$ Fujian Provincial Maternity and Children's Hospital, affiliated hospital of Fujian Medical University, Fuzhou 350001, Fujian, China. 'Department of Obstetrics and Gynecology, University-Town Hospital of Chongqing Medical University, Chongqing 401331, China. ${ }^{7}$ Chongqing Population and Family Planning Science and Technology Research Institute, 18 Honghuang Rd, Jiangbei District, Chongqing 400020, China. ${ }^{8}$ Cancer, Disease and Developmental Epigenetics, Murdoch Children's Research Institute, Parkville, Victoria 3052, Australia.

${ }^{9}$ Centre for Women's and Newborn Health, Institute of Metabolism and Systems Research, University of Birmingham, Birmingham B15 2TT, UK.

${ }^{10}$ Fetal Medicine Centre, Birmingham Women's \& Children's Foundation Trust, Edgbaston, Birmingham B15 2TG, UK. ${ }^{11}$ College of Life Sciences, University of Leicester, Leicester LE1 7RH, UK.

Received: 3 November 2020 Accepted: 10 March 2021

Published online: 08 April 2021

\section{References}

1. Foger-Samwald U, Dovjak P, Azizi-Semrad U, Kerschan-Schindl K, Pietschmann P. Osteoporosis: pathophysiology and therapeutic options. EXCLI J. 2020;19:1017-37.

2. Scheffer-Rath ME, Boot AM. The many facets of vitamin $D$ in the pediatric population. Pediatr Endocrinol Rev. 2020;17(4):293-301.

3. Al Mheid I, Quyyumi AA. Vitamin D and cardiovascular disease: controversy unresolved. J Am Coll Cardiol. 2017;70(1):89-100. https://doi.org/10.1016/j.ja cc.2017.05.031.

4. Hussain Gilani SY, Bibi S, Siddiqui A, Ali Shah SR, Akram F, Rehman MU. Obesity and diabetes as determinants of vitamin D deficiency. J Ayub Med Coll Abbottabad. 2019;31(3):432-5.

5. Khalil I, Barma P. Subcontinental atmosphere and inherent immune system may have impact on novel Corona Virus' 2019 (nCovid-19) prevalence in South East Asia. Mymensingh Med J. 2020;29(2):473-80.

6. Courbebaisse M, Souberbielle JC, Baptiste A, Taieb J, Tsatsaris V, Guibourdenche J, Senat MV, Haidar H, Jani J, Guizani M, Jouannic JM, Haguet MC, Winer N, Masson D, Elie C, Benachi A. Vitamin D status during pregnancy and in cord blood in a large prospective French cohort. Clin Nutr. 2019;38(5):2136-44. https://doi.org/10.1016/j.cInu.2018.08.035.

7. Kohler M, Leiber F, Willems H, Merbold L, Liesegang A. Influence of altitude on vitamin $\mathrm{D}$ and bone metabolism of lactating sheep and goats. J Anim Sci. 2013;91(11):5259-68. https://doi.org/10.2527/jas.2013-6702.

8. Dinlen N, Zenciroglu A, Beken S, Dursun A, Dilli D, Okumus N. Association of vitamin $D$ deficiency with acute lower respiratory tract infections in 
newborns. J Matern Fetal Neonatal Med. 2016;29(6):928-32. https://doi.org/1 $0.3109 / 14767058.2015 .1023710$

9. Cashman KD, Ritz C, Adebayo FA, Dowling KG, Itkonen ST, Ohman T, et al. Differences in the dietary requirement for vitamin $\mathrm{D}$ among Caucasian and east African women at northern latitude. Eur J Nutr. 2019;58(6):2281-91. https://doi.org/10.1007/s00394-018-1775-1.

10. Petrenya N, Lamberg-Allardt C, Melhus M, Broderstad AR, Brustad M. Vitamin D status in a multiethnic population of northern Norway: the SAMINOR 2 clinical survey. Public Health Nutr. 2020;23(7):1186-200. https://doi.org/10.1 017/S1368980018003816.

11. Elsori DH, Hammoud MS. Vitamin D deficiency in mothers, neonates and children. J Steroid Biochem Mol Biol. 2018;175:195-9.

12. Esmeraldo CUP, Martins MEP, Maia ER, Leite JLA, Ramos JLS, Goncalves J Jr, et al. Vitamin $D$ in term newborns: relation with maternal concentrations and birth weight. Ann Nutr Metab. 2019;75(1):39-46. https://doi.org/10.11 $59 / 000502044$

13. Goswami D, Rani R, Saxena A, Arora MS, Batra S, Sreenivas V. Maternal and neonatal vitamin-D status in twin versus singleton pregnancies. J Obstet Gynecol Res. 2016;42(10):1250-7. https://doi.org/10.1111/jog.13060.

14. Yoon HK. Gestational diabetes mellitus, fetal growth and vitamin D. J Bone Metab. 2017;24(3):155-9. https://doi.org/10.11005/jbm.2017.24.3.155.

15. Vijay A, Sinha S, Sindgikar SP, Shenoy VD. Effect of gestational diabetes on the vitamin D levels in the neonates: a case control study. Turk J Pediatr. 2020;62(3):431-5. https://doi.org/10.24953/turkjped.2020.03.010.

16. Curtis EM, Moon RJ, Harvey NC, Cooper C. Maternal vitamin D supplementation during pregnancy. Br Med Bull. 2018;126(1):57-77. https:// doi.org/10.1093/bmb/ldy010.

17. Perezabad L, Lopez-Abente J, Alonso-Lebrero E, Seoane E, Pion M, CorreaRocha $R$. The establishment of cow's milk protein allergy in infants is related with a deficit of regulatory T cells (Treg) and vitamin D. Pediatr Res. 2017; 81(5):722-30. https://doi.org/10.1038/pr.2017.12.

18. Kechichian E, Ezzedine K. Vitamin D and the skin: an update for dermatologists. Am J Clin Dermatol. 2018;19(2):223-35. https://doi.org/10.1 007/s40257-017-0323-8.

19. Sablok A, Batra A, Thariani K, Batra A, Bharti R, Aggarwal AR, Kabi BC, Chellani $\mathrm{H}$. Supplementation of vitamin $\mathrm{D}$ in pregnancy and its correlation with feto-maternal outcome. Clin Endocrinol. 2015;83(4):536-41. https://doi. org/10.1111/cen.12751

20. Sotunde OF, Laliberte A, Weiler HA. Maternal risk factors and newborn infant vitamin D status: a scoping literature review. Nutr Res. 2019;63:1-20.

21. Fernando S, Kumar S, Bakr M, Speicher D, Lea R, Scuffham PA, Johnson NW. Children's untreated decay is positively associated with past caries experience and with current salivary loads of mutans streptococci; negatively with self-reported maternal iron supplements during pregnancy: a multifactorial analysis. J Public Health Dent. 2019;79(2):109-15. https://doi. org/10.1111/jphd.12301.

22. Saraf R, Morton SM, Camargo CA Jr, Grant CC. Global summary of maternal and newborn vitamin D status - a systematic review. Matern Child Nutr. 2016;12(4):647-68. https://doi.org/10.1111/mcn.12210.

23. Stagi S, Rigante D. Vitamin D and juvenile systemic lupus erythematosus: lights, shadows and still unresolved issues. Autoimmun Rev. 2018;17(3):290300. https://doi.org/10.1016/j.autrev.2018.01.004.

24. Martin JA, Hamilton BE, Osterman MJK, Driscoll AK. Births: final data for 2018. Natl Vital Stat Rep. 2019;68(13):1-47.

25. Martin JA, Hamilton BE, Ventura SJ, Osterman MJ, Wilson EC, Mathews TJ. Births: final data for 2010. Natl Vital Stat Rep. 2012;61(1):1-72.

26. Ventura SJ, Martin JA, Curtin SC, Mathews TJ. Births: final data for 1997. Natl Vital Stat Rep. 1999;47(18):1-96.

27. Chang YL, Wang TH, Abufraijeh SM, Chang SD, Chao AS, Hsieh PCC Preliminary report of altered insulin secretion pattern in monochorionic twin pregnancies complicated with selective intrauterine growth restriction. Taiwan J Obstet Gynecol. 2017;56(1):51-4. https://doi.org/10.1016/j.tjog.201 5.11.004.

28. Mihaela B, Radu V, Anca B, Alexandra M, loana C, Simona V. Monochorionic vs dichorionic twins: kanet test vs postnatal neurodevelopment. Maedica (Buchar). 2020;15(1):61-70.

29. Mousa A, Abell SK, Shorakae S, Harrison CL, Naderpoor N, Hiam D, et al. Relationship between vitamin $\mathrm{D}$ and gestational diabetes in overweight or obese pregnant women may be mediated by adiponectin. Mol Nutr Food Res. 2017;61(11).
30. Karlsson T, Andersson L, Hussain A, Bosaeus M, Jansson N, Osmancevic A, Hulthén L, Holmäng A, Larsson I. Lower vitamin D status in obese compared with normal-weight women despite higher vitamin $D$ intake in early pregnancy. Clin Nutr. 2015;34(5):892-8. https://doi.org/10.1016/j.Inu.2 014.09.012.

31. Matsuda N, Taki A, Tsuji A, Nakajima K, Takasawa K, Morioka C, Minosaki Y, Oku K, Kashimada K, Morio T. Perinatal factors affecting growth and development at age 3 years in extremely low birth weight infants born small for gestational age. Clin Pediatr Endocrinol. 2018;27(1):31-8. https:// doi.org/10.1297/cpe.27.31.

32. Mathew EM, Moorkoth S, Rane PD, Lewis L, Rao P. Cost-effective HPLC-UV method for quantification of vitamin D2 and D3 in dried blood spot: a potential adjunct to newborn screening for prophylaxis of intractable pediatric seizures. Chem Pharm Bull (Tokyo). 2019;67(2):88-95. https://doi. org/10.1248/cpb.c18-00542.

33. Kovacs CS. Vitamin D in pregnancy and lactation: maternal, fetal, and neonatal outcomes from human and animal studies. Am J Clin Nutr. 2008; 88(2):520S-8S. https://doi.org/10.1093/ajcn/88.2.520S.

34. Traglia M, Windham GC, Pearl M, Poon V, Eyles D, Jones KL, Lyall K, Kharrazi $M$, Croen LA, Weiss LA. Genetic contributions to maternal and neonatal vitamin D levels. Genetics. 2020;214(4):1091-102. https://doi.org/10.1534/ genetics.119.302792.

35. Wei F, Wang Z, Wang J, Xu H, Zhou H. Serum vitamin D levels among children aged 0-12 years in the first affiliated Hospital of Harbin Medical University, China. J Public Health (Oxf). 2018;40(4):721-6. https://doi.org/10.1 093/pubmed/fdy055.

36. Wang Y, Li H, Zheng M, Wu Y, Zeng T, Fu J, Zeng D. Maternal vitamin D deficiency increases the risk of adverse neonatal outcomes in the Chinese population: a prospective cohort study. PLoS One. 2018;13(4):e0195700. https://doi.org/10.1371/journal.pone.0195700.

37. Zhu T, Liu TJ, Ge X, Kong J, Zhang LJ, Zhao Q. High prevalence of maternal vitamin $D$ deficiency in preterm births in northeast China, Shenyang. Int J Clin Exp Pathol. 2015;8(2):1459-65.

38. Windham GC, Pearl M, Anderson MC, Poon V, Eyles D, Jones KL, Lyall K, Kharrazi M, Croen LA. Newborn vitamin $D$ levels in relation to autism spectrum disorders and intellectual disability: a case-control study in California. Autism Res. 2019:12(6):989-98. https://doi.org/10.1002/aur.2092.

39. Ariyawatkul $K$, Lersbuasin P. Prevalence of vitamin D deficiency in cord blood of newborns and the association with maternal vitamin D status. Eur J Pediatr. 2018;177(10):1541-5. https://doi.org/10.1007/s00431-018-3210-2.

40. Al Zarooni AAR, Al Marzougi Fl, Al Darmaki SH, Prinsloo EAM, Nagelkerke N. Prevalence of vitamin $D$ deficiency and associated comorbidities among Abu Dhabi Emirates population. BMC Res Notes. 2019;12(1):503. https://doi. org/10.1186/s13104-019-4536-1.

41. Fan H, Hui L, Yan X, Hou W, Bai E, Wang L, Yu X. Serum 25 hydroxyvitamin $D$ levels and affecting factors among preconception fertile women. BMC Womens Health. 2020;20(1):146. https://doi.org/10.1186/s12905-020-01018-1.

42. Yu X, Wang W, Wei Z, Ouyang F, Huang L, Wang X, Zhao Y, Zhang H, Zhang J. Vitamin D status and related factors in newborns in Shanghai, China. Nutrients. 2014;6(12):5600-10. https://doi.org/10.3390/nu6125600.

43. Shor DB, Barzel J, Tauber E, Amital H. The effects of maternal vitamin D on neonatal growth parameters. Eur J Pediatr. 2015;174(9):1169-74. https://doi. org/10.1007/s00431-015-2517-5.

44. Yun C, Chen J, He Y, Mao D, Wang R, Zhang Y, Yang C, Piao J, Yang X. Vitamin $D$ deficiency prevalence and risk factors among pregnant Chinese women. Public Health Nutr. 2017;20(10):1746-54. https://doi.org/10.1017/ S1368980015002980

\section{Publisher's Note}

Springer Nature remains neutral with regard to jurisdictional claims in published maps and institutional affiliations. 